\title{
Beta-Elemene Suppresses Metastasis of Human Esophageal Cancer Cell by Downregulating Heat Shock Protein 70/Mothers against Decapentaplegic Homolog 2 Pathway
}

\author{
W. C. GAO ${ }^{1}$ AND W. J. CHEN ${ }^{1 *}$
}

Department of Oncology, The Second Affiliated Hospital of Zhejiang Chinese Medical University, ${ }^{1}$ The Second Clinical Medical School of Zhejiang Chinese Medical University, Zhejiang Province, Hangzhou 310000, China

Gao et al.: Beta-Elemene Suppresses Metastasis of Human Esophageal Cancer Cell

\begin{abstract}
In this study, we tried to illuminate the role and underlying mechanism of beta-elemene in esophageal squamous cell carcinoma especially the metastasis. 3-(4, 5-dimethylthiazolyl-2)-2, 5-diphenyltetrazolium bromide assay was performed to determine the cytotoxicity of beta-elemene and its role in esophageal squamous cell carcinoma cell proliferation. Wound healing assay and transwell assays were used to elucidate the roles of betaelemene on cell migration and invasion abilities of esophageal squamous cell carcinoma cells. Quantitative polymerase chain reaction and western blot assays were carried out to assess the messenger RNA and protein expression under beta-elemene treatment. Immunofluorescence staining was performed to detect the heat shock protein 70 expression regulated by beta-elemene. The heat shock protein 70 ectopic expression plasmid was used to perform the rescue experiments. In this study, we found that beta-elemene significantly inhibited the cell survival and cell proliferation and suppressed cell migration and invasion abilities of esophageal squamous cell carcinoma cell line. Mechanistically, we observed that beta-elemene downregulated heat shock protein 70 expressions and reversed epithelial-mesenchymal transition. Furthermore, the studies also indicated that beta-elemene downregulated the phosphorylation of extracellular regulated kinase, mothers against decapentaplegic homolog 2 and mothers against decapentaplegic homolog 3 expression. In addition, we confirmed that ectopic expression of heat shock protein 70 not only promoted cell migration, epithelialmesenchymal transition and mothers against decapentaplegic homolog 2 phosphorylation in esophageal squamous cell carcinoma cell line cells, but also reversed beta-elemene suppressed cell migration in TE-1 cells. Taken together, all results elucidated that beta-elemene suppresses metastasis of human esophageal squamous cell carcinoma by modulating the expression of heat shock protein 70 and the activation of extracellular regulated kinase and transforming growth factor beta signaling pathways at least partially.
\end{abstract}

Key words: Beta-elemene, immunofluorescence staining, heat shock protein 70, mothers against decapentaplegic homolog 2

Esophageal Squamous Cell Carcinoma (ESCC), one of the major histological subclasses of esophageal cancer in developing nations, is a malignancy connected with high mortality worldwide, which also have a high incidence and mortality rate in China ${ }^{[1,2]}$. Multidisciplinary treatment choices for ESCC patients may select surgery, chemotherapy and radiotherapy scheme ${ }^{[3]}$. Unfortunately, due to its invasive, metastatic potential and poor response to chemoradiotherapy, the overall survival rate for $5 \mathrm{y}$ on ESCC patients is approximately $10 \%{ }^{[4]}$. Therefore, it's urgently requisite to unveil the progress of metastasis and seek more effective therapeutic methods or targets to treat ESCC, especially the metastatic one.

The Chinese anticancer medicine beta-elemene ( $\beta$-elemene) is a nature monomer isolated from the Curcuma wenyujin and has been shown to exhibit anticancer activity in several cancer types, such as breast cancer ${ }^{[5]}$, non-small cell lung cancer ${ }^{[6]}$, ovarian cancer $^{[7]}$, colorectal cancer $^{[8]}$, glioblastoma ${ }^{[9]}$, renal cancer $^{[10]}$, leukemia ${ }^{[11]}$ and $\mathrm{ESCC}^{[12]}$. For instance, $\beta$-elemene exhibits these anticancer effects by

*Address for correspondence

E-mail: 3546730778@qq.com 
suppressing proliferation and inducing apoptosis ${ }^{[13,14]}$. Recent studies demonstrate that $\beta$-elemene suppresses metastasis in thyroid carcinoma ${ }^{[15]}$, gastric cancer ${ }^{[16]}$, breast cancer ${ }^{[17]}$, melanoma ${ }^{[18]}$ and laryngeal carcinoma $^{[19]}$. Recently, it was reported that $\beta$-elemene could suppress the malignant behavior of esophageal cancer cells by regulating the phosphorylation of protein kinase B (AKT $)^{[12]}$. However, whether $\beta$-elemene could influence the metastasis of ESCC and the underlying mechanism remain to be fully illustrated.

In the present study, we evaluated the effects of $\beta$-elemene on the cell cytotoxicity, cell proliferation, migration and invasion potentials of ESCC cells by using 3-(4, 5-dimethylthiazolyl-2)-2, 5-diphenyltetrazolium bromide (MTT) assay, western blot assay, wound healing assay, transwell assays. Our data suggested that $\beta$-elemene suppresses metastasis of human ESCC by modulating Heat Shock Protein 70 (HSP70)/mothers against decapentaplegic homolog $2(\operatorname{Smad} 2)$ pathways. Our data thus indicate that $\beta$-elemene is possibly an effective and a great promising agent for further development to treat metastatic ESCC.

\section{MATERIALS AND METHODS}

\section{Cell culture:}

The human ESCC cell line (TE-1) (TCHu 89) was purchased from the cell bank of type culture collection of Chinese Academy of Sciences (Shanghai, China) and cultured in Dulbecco's modified eagle medium (DMEM) (Gibco) supplied with $100 \mu \mathrm{g} / \mathrm{ml}$ of streptomycin (Gibco), $100 \mathrm{U} / \mathrm{ml}$ of penicillin (Gibco) and $10 \%$ fetal bovine serum (FBS) (Hyclone) in a humidified incubator with an atmosphere of $5 \%(\mathrm{v} / \mathrm{v})$ $\mathrm{CO}_{2}$ at $37^{\circ}$.

\section{Cell viability and proliferation assay:}

The cell viability of ESCC TE-1 cells treated with $\beta$-elemene was tested in 96 well plates by using the MTT assay. In brief, the TE- 1 cells were seeded into 96 well plates at a density of 5000 cells/well and allowed to attach overnight. After that, $\beta$-elemene was added with variable concentrations in medium. The TE-1 cells were exposed to $\beta$-elemene for $24 \mathrm{~h}$ followed by the MTT assay to determine cell survival rates. The GraphPad Prism software was calculated the halfmaximal inhibitory concentration $\left(\mathrm{IC}_{50}\right)$ values and for cell proliferation, TE-1 cells were incubated with $\beta$-elemene $(100 \mu \mathrm{g} / \mathrm{ml}, 150 \mu \mathrm{g} / \mathrm{ml})$ for $24 \mathrm{~h}, 48 \mathrm{~h}, 72 \mathrm{~h}$ and $96 \mathrm{~h}$. After that, the cells are followed by the MTT assay to determine cell proliferation. The absorbance of each sample was read at $570 \mathrm{~nm}$ using a microplate reader (Molecular device).

\section{Wound healing assay:}

The TE- 1 cells were seeded into 6 well culture plates and allowed to $100 \%$ confluence in full growth medium. Then the cells were starved for overnight in serum-free medium. A plastic pipette tip was used to generate a clean wound area. The cell debris was removed by washing with Phosphate Buffered Saline (PBS) and the TE-1 cells were allowed to migrate in serum-free DMEM medium with $\beta$-elemene $(100 \mu \mathrm{g} / \mathrm{ml})$ for 24 , 48 and $72 \mathrm{~h}$. The images of the wound healing process were photographed by an Olympus microscope.

\section{In vitro migration and invasion assays:}

For the migration assay, the transwell $(8 \mu \mathrm{m}$ pore size with poly-carbonate membrane, Corning) were used according to the manufacturer's protocols. The TE-1 cells were seeded into the upper chambers using serumfree DMEM medium. The lower compartment was placed in 24 cell plate filled with DMEM medium with $15 \%$ FBS as a chemoattractant. After incubation for $24 \mathrm{~h}$, the cells remaining in the upper chamber were removed by cotton swab and the cells at the bottom of the insert were fixed with iced methanol, stained in $0.5 \%$ crystal violet and counted under a microscope (Olympus). The results were averaged over three independent experiments. For invasion assays, the inserts were pre-coated with Matrigel (BD) before the cells were added and the following steps are the same as migration assay.

\section{RNA isolation and quantitative polymerase chain reaction (qPCR):}

Total RNA was isolated from the TE-1 cell lines by using the Trizol reagent (Invitrogen) according to the manufacturer's protocols. Complementary DNA synthesis of messenger RNA (mRNA) was performed using Moloney Murine Leukemia Virus (M-MLV) reverse transcriptase (Promega Corporation) according to the manufacturer's protocols. The relative expression levels of E-cadherin, N-cadherin, vimentin and Snail mRNA were evaluated using qPCR with a SYBR green PCR master mix (Applied Biosystems) and calculated using the $2^{-\Delta \Delta \mathrm{Ct}}$ method by normalizing with $\beta$-actin. The PCR reaction was performed in ABI7300 PCR thermocycle instrument and the thermocycling conditions were as follows: $95^{\circ}$ for $10 \mathrm{~min}, 45$ cycles of $95^{\circ}$ for $15 \mathrm{sec}$ and $60^{\circ}$ for $1 \mathrm{~min}$. All reactions were performed in triplicate and the primer sequences are listed in Table 1. 


\begin{tabular}{|c|c|}
\hline Gene & Sequences \\
\hline \multirow[t]{2}{*}{ E-cadherin } & Forward: 5'-ACACCCGATTCAAAGTGG-3' \\
\hline & Reverse: 5'-GTTGGGAAATGTGAGCAAA-3' \\
\hline \multirow[t]{2}{*}{$\mathrm{N}$-cadherin } & Forward: 5'-TTTGCCCCCAATCCTAAG-3' \\
\hline & Reverse: 5’-GCAGCGTTCCTGTTCCAC-3’ \\
\hline \multirow[t]{2}{*}{ Vimentin } & Forward: 5'-TGCGTGAAATGGAAGAGAACTT-3' \\
\hline & Reverse: 5'-TGGGTATCAACCAGAGGGAGTG-3' \\
\hline \multirow[t]{2}{*}{ Snail } & Forward: 5'-CCCAGCCCCAGCTACCACCT-3' \\
\hline & Reverse: 5'-GCCCССТСТССТСТTССTTCTC-3' \\
\hline \multirow[t]{2}{*}{ B-actin } & Forward: 5'-AGCACAGAGCCTCGCCTT TGC-3' \\
\hline & Reverse 5'-CTGTAGCCGCGCTCGGTGAG-3' \\
\hline
\end{tabular}

\section{Western blotting:}

The TE-1 cells were lysed in Radioimmunoprecipitation Assay (RIPA) buffer containing phosphatase and protease inhibitor cocktail (Sigma) for protein extraction. After electrophoresis on $12 \%$ or 15 $\%$ Sodium Dodecyl-Sulfate Polyacrylamide Gel Electrophoresis (SDS-PAGE), proteins were transferred onto Polyvinylidene Fluoride (PVDF) membranes. The membranes were blocked with $5 \%$ milk and followed by incubation with primary antibodies against E-cadherin (CST, No. 14472), N-cadherin (Proteintech, No. 22018-1-AP), vimentin (CST, No. 5741), betacatenin ( $\beta$-catenin) (CST, No. 8480), HSP70 (CST, No.4873), extracellular regulated kinase (ERK) (Proteintech, No.20874-AP), Smad2 (CST, No.5339), Smad3 (CST, No.9523), phosphorylated form of ERK (p-ERK) (CST, No.4370), phosphorylated Smad2 (p-Smad2) (CST, No.18338) and phosphorylated Smad3 (p-Smad3) (CST, No.9520) at $4^{\circ}$ overnight. The Horseradish Peroxidase (HRP) conjugated secondary antibody was added and incubated for $1 \mathrm{~h}$. Signals were visualized after chemiluminescence reaction with HRP substrate. $\beta$-actin was used as a loading control and its antibody was purchased from Sigma with dilution at 1:5000. All other primary antibodies were obtained from cell signaling technology and diluted at 1:1000.

\section{Immunofluorescence for forkhead box class $O$ 3a (FOXO3a) detection:}

The TE-1 cells were seeded in 6 well plates and allowed to attach overnight. After that, $\beta$-elemene $(100 \mu \mathrm{g} / \mathrm{ml})$ was added and incubated for $24 \mathrm{~h}$. The immunofluorescence staining of HSP70 was processed according to the manufacture's instruction. Briefly, the TE- 1 cells were fixed in iced $4 \%$ formaldehyde for $30 \mathrm{~min}$. The cells are incubated with cell permeable solution for 5 min. HSP70-Alexa Fluor 594 (AF594) antibody were added and allowed to incubate for $1 \mathrm{~h}$ and then nuclei were stained with 4',6-Diamidino2-Phenylindole Dihydrochloride (DAPI) (1 $\mu \mathrm{g} / \mathrm{ml})$. Fluorescent images were taken with an Olympus fluorescent microscope.

\section{Plasmid construction and transfection:}

The coding sequences of human HSP70 mRNA were synthesized and digested with type II site-specific deoxyribonuclease restriction enzyme (HindIII) and Restriction Endonuclease (EcoRI) and subcloned into plasmid cloning DNA (pcDNA) 3.1 vector. The integrity of the respective plasmid constructs was confirmed by DNA sequencing. The plasmid was incubated with lipofectamine 2000 reagent (Invitrogen) for $20 \mathrm{~min}$ at room temperature to form complex and transfection was carried out at $37^{\circ}$ for $24 \mathrm{~h}$.

\section{Statistical analysis:}

All statistical analyses were performed using GraphPad Prism 5.0 (GraphPad Software, Inc., La Jolla, CA, USA). All data are expressed as the mean \pm Standard Deviation (SD) from atleast 3 independent experiments. Statistical significance was determined using twosided Student's $t$ test and $\mathrm{p}<0.05\left(^{*}\right)$ was considered significantly change.

\section{RESULTS AND DISCUSSION}

$\beta$-elemene inhibited human ESCC TE-1 cell growth. $\beta$-elemene is classified as sesquiterpene and its chemical structure was shown in fig. 1A. At first, MTT assay was performed to investigate the cytotoxicity of $\beta$-elemene in human ESCC cell line TE-1. As shown in fig. $1 \mathrm{~B}$, the results showed that $24 \mathrm{~h}$ treatment of $\beta$-elemene significantly suppressed TE- 1 cell survival in a dose-dependent manner, although low dose of $\beta$-elemene (40 and $80 \mu \mathrm{g} / \mathrm{ml}$ ) slightly promoted cell survival. Additionally, the cell proliferation of TE-1 
under $\beta$-elemene treatment was detected also by MTT assay. As shown in fig. $1 \mathrm{C}$, the data revealed that 100 $\mu \mathrm{g} / \mathrm{ml}$ or $150 \mu \mathrm{g} / \mathrm{ml} \beta$-elemene could significantly inhibit TE-1 cell proliferation, especially after $48 \mathrm{~h}$ treatment. Therefore, these results demonstrated that $\beta$-elemene exerted remarkably cytotoxicity in TE- 1 cell by inhibiting cell growth.

$\beta$-elemene suppressed the cell migration and invasion in TE- 1 cells. To examine the effect of $\beta$-elemene on cell migration and invasion abilities in ESCC, wound healing and transwell assays were utilized. As illustrated in fig. $2 \mathrm{~A}$ and fig. $2 \mathrm{~B}$, we found that $100 \mu \mathrm{g} / \mathrm{ml} \beta$-elemene significantly slowed the rate of TE-1 cells into the wounded area compared to the control group at $24 \mathrm{~h}$, $48 \mathrm{~h}$ and $72 \mathrm{~h}$. On other hand, cell migration potential under $\beta$-elemene treatment was determined using the transwell without Matrigel. As illustrated in fig. $2 \mathrm{C}$ and fig. $2 \mathrm{D}$, we demonstrated that $100 \mu \mathrm{g} / \mathrm{ml} \beta$-elemene dramatically decelerated the migrated cells into the bottom of the insert area compared to the control group at $24 \mathrm{~h}$. In addition, as also shown in fig. $2 \mathrm{C}$ and fig. 2D, using the transwell assays with Matrigel, we found that $100 \mu \mathrm{g} / \mathrm{ml} \beta$-elemene prominently reduced the cell invasion into the bottom of the insert area compared to the control group at $24 \mathrm{~h}$. Therefore, these results illuminated that $\beta$-elemene noticeably suppressed both cell migration and invasion abilities of TE-1 cells. $\beta$-elemene reversed Epithelial-Mesenchymal Transition (EMT) and decreased HSP70 expression in TE-1 cells were investigated. EMT is a key initiate step for cancer metastasis and plays an important role in cancer migration and invasion. To investigate the underlying mechanisms of the role of $\beta$-elemene on ESCC, the expression of EMT-related biomarkers under $\beta$-elemene treatment were analyzed by qPCR and western blot assays. As shown in fig. 3A, using the $\mathrm{qPCR}$ assay, we found that $\beta$-elemene noticeably upregulated epithelial marker E-cadherin and downregulated the mesenchymal markers vimentin, $\mathrm{N}$-cadherin and EMT-related transcription factor snail on mRNA level. Furthermore, as shown in fig. 3B and fig. $3 \mathrm{C}$, using the western blot assay, we certified that $\beta$-elemene obviously upregulated epithelial marker E-cadherin, downregulated the mesenchymal marker vimentin, but no statistical difference on $\mathrm{N}$-cadherin and $\beta$-catenin. More interestingly, $\beta$-elemene significantly suppressed the expression of HSP70 at both mRNA and protein levels (fig. 3A-3C). Moreover, the date of immunofluorescence assay also indicated that $\beta$-elemene inhibited HSP70 expression in TE-1 cells (fig. 3D). Therefore, these results confirmed that $\beta$-elemene reversed EMT and markedly decreased HSP70 expression in TE-1 cells. However, whether HSP70 was involved in the role of $\beta$-elemene and EMT remains to be further illuminated.
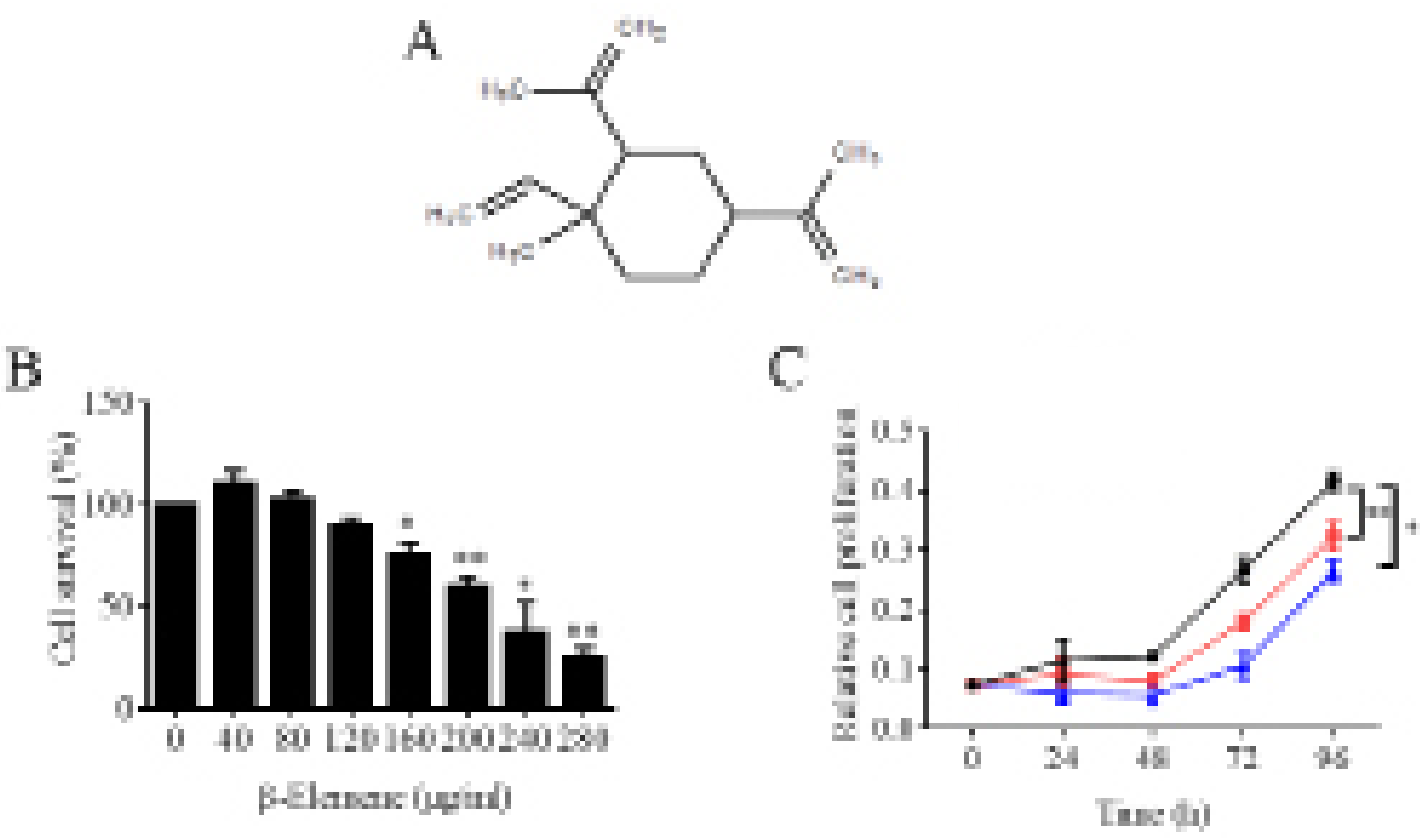

Fig. 1: $\beta$-elemene inhibited human esophageal cancer cell growth in vitro. (A) Chemical structure of $\beta$-elemene; (B) Cytotoxicity of $\beta$-elemene on human esophageal cancer cell TE-1; (C) $\beta$-elemene inhibited human esophageal cancer cell proliferation. The TE-1 was incubated in the indicated concentrations of $\beta$-elemene for $24 \mathrm{~h}, 48 \mathrm{~h} 72 \mathrm{~h}$ and $96 \mathrm{~h}$. Cell viability was determined by MTT assay. Each point represents the mean of the data of three independent experiments, ${ }^{*} \mathrm{p}<0.05 ;{ }^{* *} \mathrm{p}<0.01 v s . \operatorname{control} .(+) 0 \mu \mathrm{g} / \mathrm{ml}$; $(+) 100$ $\mu \mathrm{g} / \mathrm{ml} ;(+) 150 \mu \mathrm{g} / \mathrm{ml}$ 


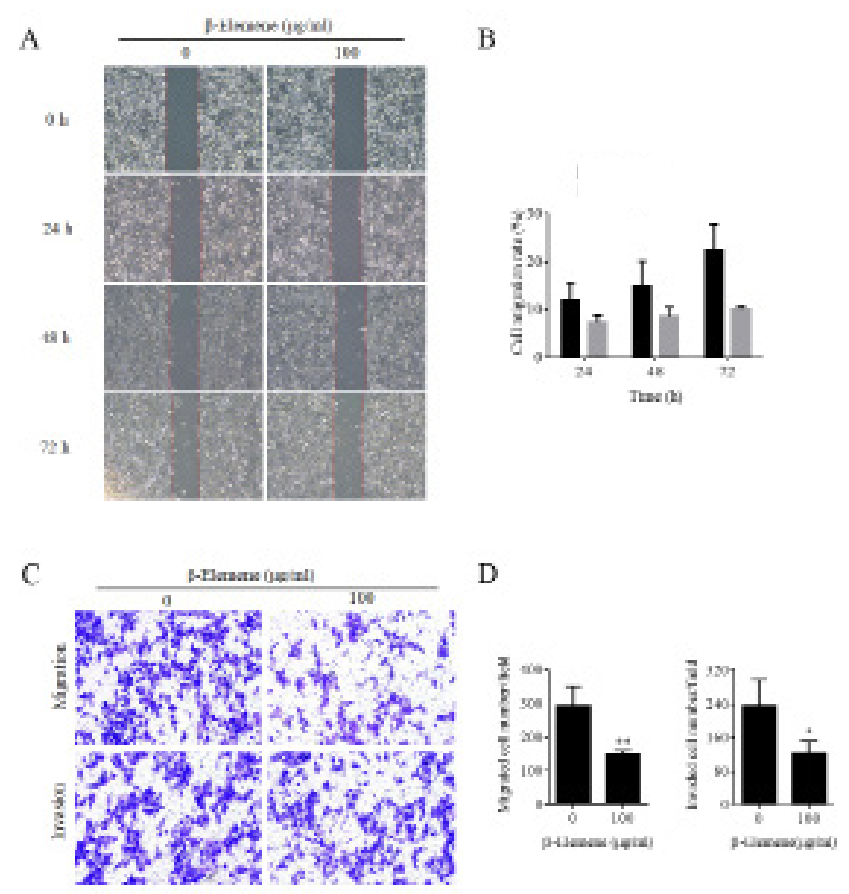

Fig. 2: Low dosage of $\beta$-elemene suppressed human esophageal cancer cell migration and invasion. (A) Representative images of wound healing processes of TE-1 cells treated with $\beta$-elemene $(100 \mu \mathrm{g} / \mathrm{ml})$ for $24 \mathrm{~h}, 48 \mathrm{~h}$ and $72 \mathrm{~h}$; (B) Quantitative analysis of cell migration rate of wound healing assay. The data are presented as the mean \pm SD of three independent experiments; (C) Representative images of transwell migration and invasion assays of TE-1 cells treated with $\beta$-elemene $(100 \mu \mathrm{g} / \mathrm{ml})$ for $24 \mathrm{~h}$; (D) Quantitative analysis of migrated and invaded cell of transwell assay. The data are presented as the mean \pm SD of three independent experiments. Each point represents the mean of the data of three independent experiments, *p<0.05; **p<0.01 vs. control. ( E) $0 \mu \mathrm{g} / \mathrm{ml}$; ( $\mid=$ ) $100 \mu \mathrm{g} / \mathrm{ml}$
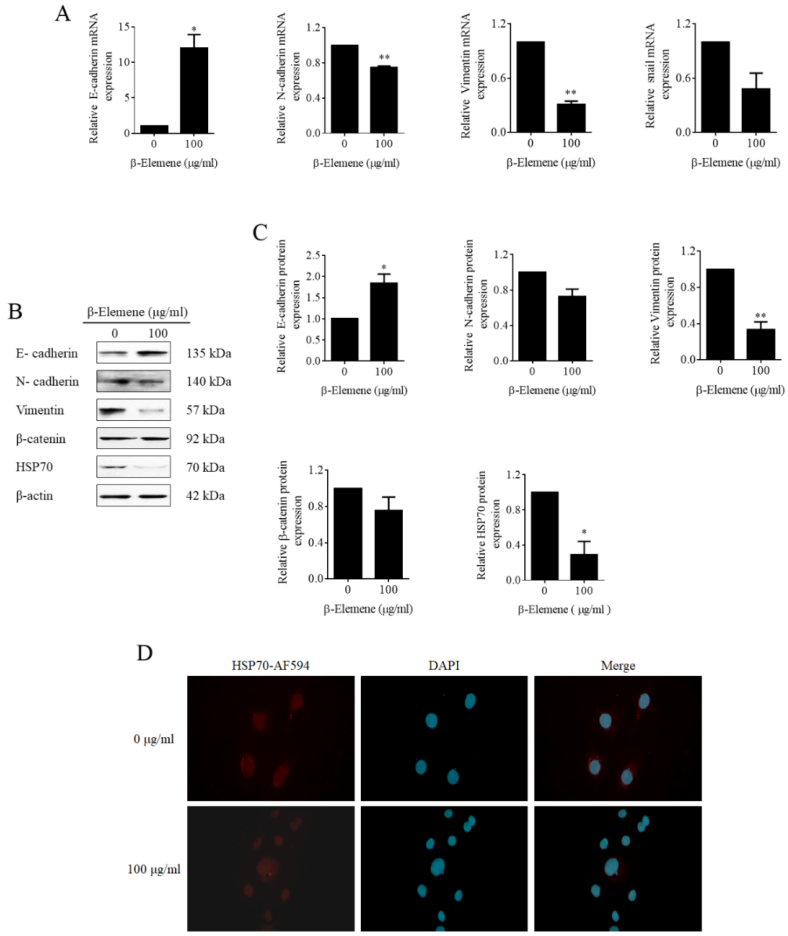

Fig. 3: $\beta$-elemene reversed human esophageal cancer cell EMT and decreased HSP70 expression. TE-1 cells were cultured in the presence of $\beta$-elemene $(100 \mu \mathrm{g} / \mathrm{ml})$ for $24 \mathrm{~h}$, (A) RT-qPCR analysis of E-cadherin, $\mathrm{N}$-cadherin, vimemtin and snail mRNA expression level; (B) Western blot analysis of E-cadherin, $\mathrm{N}$-cadherin, vimemtin, $\beta$-catenin and HSP70 expression level, $\beta$-actin was used as a loading control; (C) Quantitative analysis expression of proteins in B. The data are presented as the mean \pm SD of three independent experiments, *p<0.05; ** $<0.01$ vs. control; (D) Immunofluorescent images of HSP70. The HSP70 was recognized by red fluorescence conjugated antibody HSP70-AF594 and nuclei were stained with DAPI. The data are derived from one of the three independent experiments 
$\beta$-elemene inhibited phosphorylation of ERK, Smad2 and Smad3. Increasing evidences have reported that HSP70 was involved in the activation of MitogenActivated Protein Kinases (MAPK)/ERK and transforming growth factor beta (TGF- $\beta$ ) signaling pathways $^{[20-23]}$. To further confirm whether $\beta$-elemene induced HSP70 inhibition influenced the activation of these two signaling pathways, western blot assay was performed. As shown in (fig. 4A and fig. 4B), the results declared that $\beta$-elemene dramatically inhibited phosphorylation of ERK Smad 2 and Smad3, suggesting that $\beta$-elemene treatment inactivated both MAPK/ERK and TGF- $\beta$ signaling.

Ectopic expression of HSP70 reversed $\beta$-elemenesuppressed cell migration in TE-1 cells. Next, to prove the function of HSP70 in role of $\beta$-elemene in ESCC metastasis, HSP70 overexpression plasmid was constructed and transfection was performed in
TE-1 cells to overexpress HSP70. As expected, the transwell assays manifested that the ectopic expression of HSP70 significantly promoted the cell migration of TE-1 cells (fig. 5A and fig. 5B). In addition, as shown in fig. $5 \mathrm{C}$ and fig. 5D, we found that overexpression of HSP70 prominently downregulated epithelial marker E-cadherin and upregulated the mesenchymal markers vimentin, but play a weak role in N-cadherin expression. Moreover, overexpression of HSP70 induced phosphorylation of Smad2 without affecting phosphorylation of ERK and Smad3 (fig. 5E and fig. 5F). Furthermore, the data of transwell assays without Matrigel, we enunciated that overexpression of HSP70 reversed $\beta$-elemene-suppressed cell migration in TE-1 cells (fig. 6A and fig. 6B). Therefore, the results illustrated that $\beta$-elemene-suppressed cell migration in TE- 1 cells by suppressing EMT and inactivating TGF- $\beta$ / SMAD2 signaling pathway in a HSP-70 independent manner at least partially.

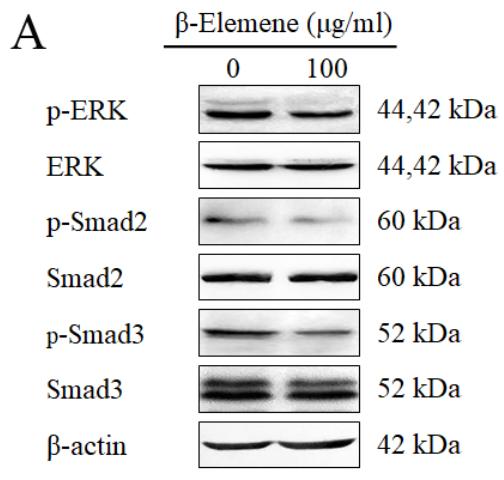

B
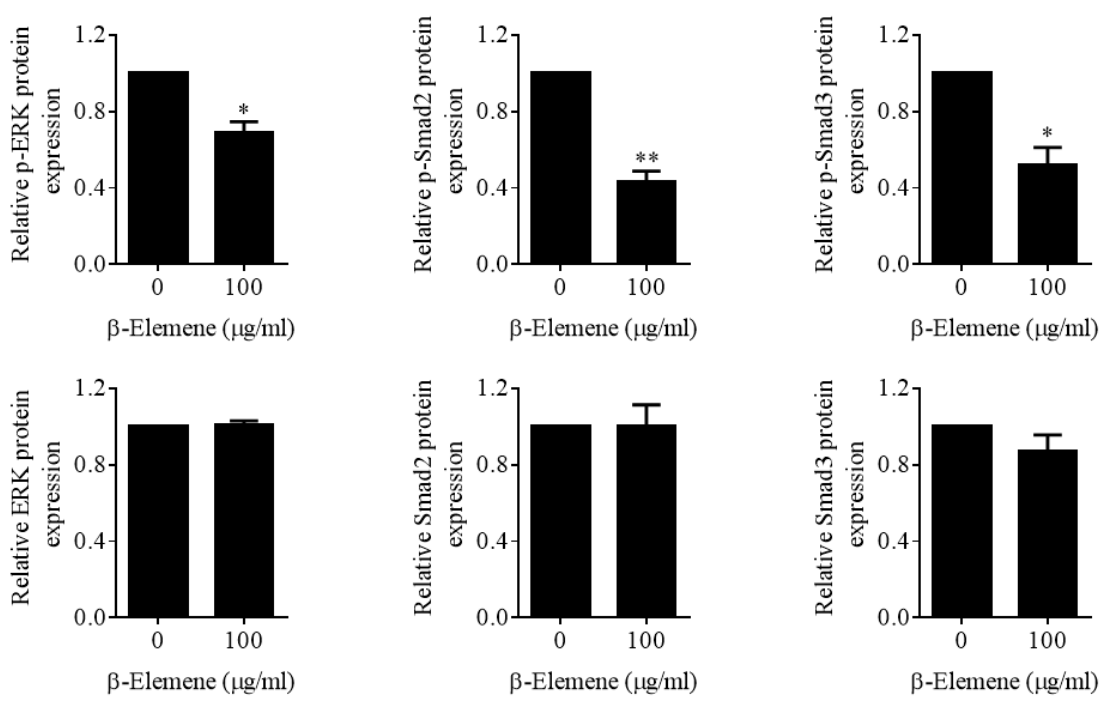

Fig. 4: $\beta$-elemene inhibited the phosphorylation of ERK, Smad2 and Smad3. TE-1 cells were cultured in the presence of $\beta$-elemene $(100 \mu \mathrm{g} / \mathrm{ml})$ for $24 \mathrm{~h}$. (A) Western blot was used to detect the phosphorylation of ERK, Smad2 and Smad3, $\beta$-actin was used as a loading control; (B) Quantitative analysis expression of proteins in A. The data are presented as the mean \pm SD of three independent experiments, ${ }^{*} \mathbf{p}<0.05 ; * * \mathbf{p}<0.01$ vs. control 
A

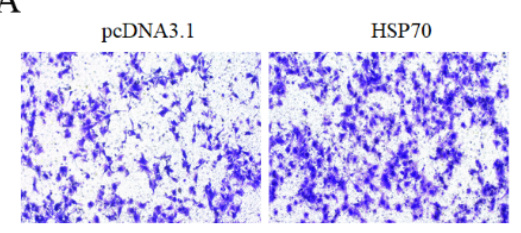

B

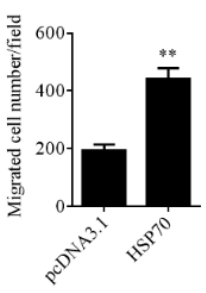

$\mathrm{C}$

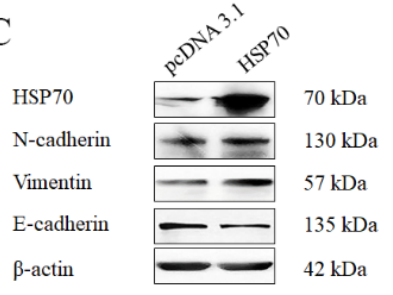

E

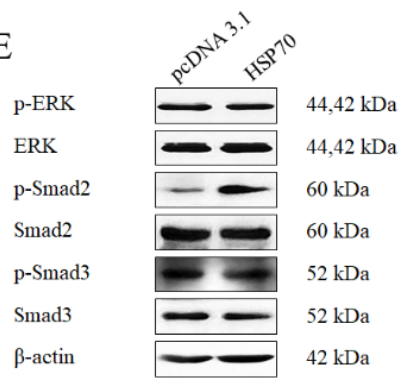

$\mathrm{D}$
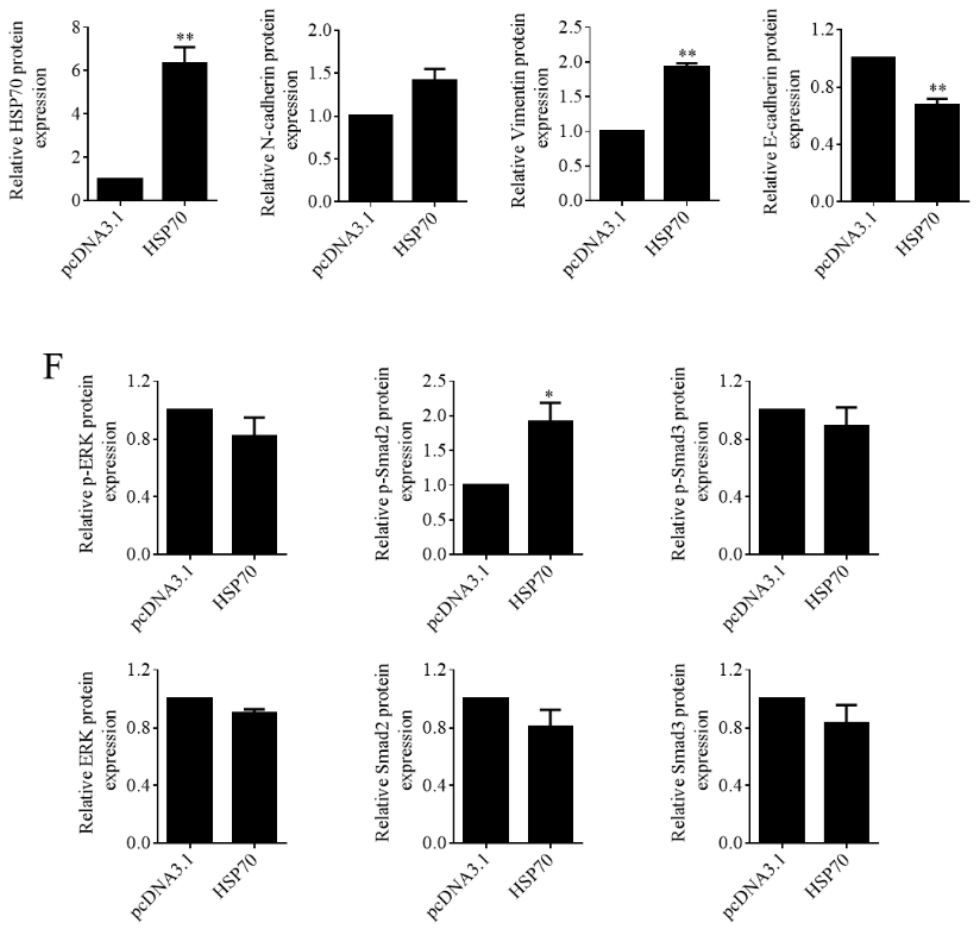

Fig. 5: Ectopic expression of HSP70 promoted cell migration, EMT and Smad2 phosphorylation in TE-1 cells, TE-1 cells transfected with control vector or HSP70-expressing vector for $24 \mathrm{~h}$. (A) Representative images of transwell migration assays; (B) Quantitative analysis of migrated cell of transwell assay. The data are presented as the mean \pm SD of three independent experiments, $* * p<0.01 v s$. control; (C) Western blot analysis of HSP70, N-cadherin, vimemtin and E-cadherin expression level, $\beta$-actin was used as a loading control; (D) Quantitative analysis expression of proteins in C. The data are presented as the mean \pm SD of three independent experiments, **p<0.01 vs. control; (E) Western blot analysis of ERK, Smad2, Smad3, p-ERK, p-Smad2 and p-Smad3 expression level, $\beta$-actin was used as a loading control; (F) Quantitative analysis expression of proteins in $\mathrm{E}$. The data are presented as the mean \pm SD of three independent experiments, ${ }^{*} \mathbf{p}<0.05$ vs. control

A

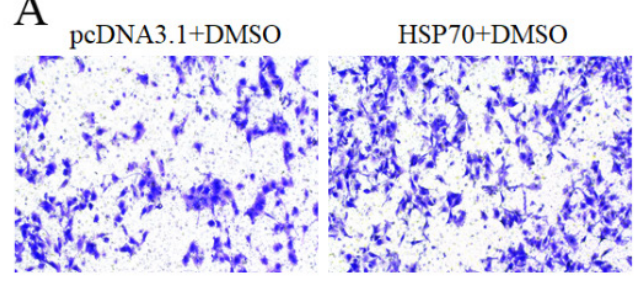

pcDNA3.1+ $\beta$-Elemene

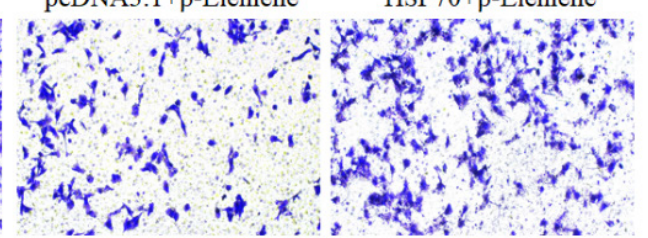

B

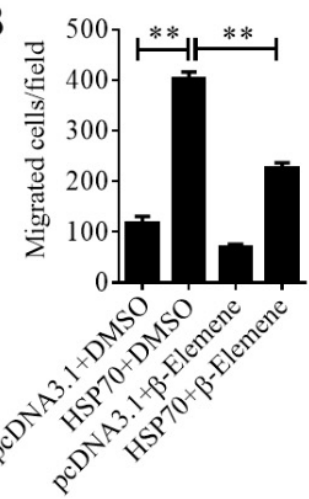

Fig. 6: Ectopic expression of HSP70 reversed $\beta$-elemene-suppressed cell migration in TE-1 cells. (A) Representative images of transwell migration assay of TE-1 cells that transfected with control vector or HSP70 expressing vector with or without treated with $\beta$-elemene $(100 \mu \mathrm{g} / \mathrm{ml})$ for $24 \mathrm{~h}$; (B) Quantitative analysis of migrated cell of transwell assay in A. The data are presented as the mean \pm SD of three independent experiments, ${ }^{* *} \mathbf{p}<0.01 v$ s. control 
Metastasis is generally the predominant obstacles in therapy of human cancer, including ESCC which have advanced metastatic ability at first time diagnosis ${ }^{[4]}$. In this study, we investigated the anticancer effect of $\beta$-elemene on human ESCC. Here, we found that $\beta$-elemene dramatically suppressed ESCC TE-1 cell viability, proliferation and restraining cell migration and invasion abilities. Mechanistically, our data revealed that $\beta$-elemene suppressed the EMT and downregulated HSP70 expression. Recent studies showed that HSP70 had molecular chaperone, cytoprotective, anti-inflammatory and anti-apoptotic properties ${ }^{[20,24,25]}$. Moreover, the studies also revealed that the HSP70 basal level was higher in some types of malignancies and that it has been classified as a bad prognosis element ${ }^{[26-28]}$. Although the research about the expression and biological role of HSP70 in esophageal cancer are relatively limited, it has been reported higher levels of HSP70 was detected in esophageal cancer compared with normal tissues ${ }^{[29]}$. Compliance with these parts of evidence, our results indicated that overexpression of HSP70 could significantly promote cell migration, EMT and Smad2 phosphorylation in ESCC cells.

Cancer cell motility, including invasion and migration, is one of multi-step processes of metastasis ${ }^{[30]}$. In this study, we illuminated that $\beta$-elemene noticeably suppressed ESCC cell migration and invasion, while overexpression of HSP70 prominently increased ESCC cell migration and reversed $\beta$-elemene blocked cell migration. Furthermore, the studies declared that EMT was also closely correlated with tumor metastasis $^{[30,31]}$. In this study, we demonstrated that $\beta$-elemene markedly upregulated epithelial marker E-cadherin, downregulated the mesenchymal marker vimentin, while overexpression of HSP70 remarkably downregulated epithelial marker E-cadherin and upregulated the mesenchymal markers vimentin, $\mathrm{N}$-cadherin.

Subsequently, it has been well documented that MAPK/ERK and TGF- $\beta$ signaling pathways take part in progression of many cancers including ESCC progression $^{[32-34]}$. To further understand the antimetastatic mechanism of $\beta$-elemene, we analyzed the phosphorylation of Smad-2 and Smad-3 by western blot. The results showed that $\beta$-elemene remarkably inhibited phosphorylation of Smad2 and Smad3, while overexpression of HSP70 induced phosphorylation of Smad2 without affecting phosphorylation of Smad3.
Finally, we found that downregulation of phosphorylated ERK was involved in the $\beta$-elemene inhibited ESCC metastasis. However, the overexpression of HSP70 did not influence the phosphorylation of ERK.

To conclude, we acknowledged in our study that $\beta$-elemene suppresses metastasis of human ESCC by modulating HSP70/Smad2 pathway. It could be a promising anti-metastasis strategy for ESCC treatment. However, there were still some limitations to be an effective agent in metastatic ESCC treatment. In our follow-up study, we will do more research about in vivo experiments and ESCC patients are requirement to develop our current findings.

\section{Acknowledgements:}

This work was supported by Science and Technology Project Planning of Traditional Chinese Medicine in Zhejiang Province (No. 2018ZB064) and Zhejiang Key Subject Project of Traditional Chinese Medicine (No. 2017-XK-A12).

\section{Conflicts of interest:}

The authors declared no conflict of interest.

\section{REFERENCES}

1. Chen W, Zheng R, Baade PD, Zhang S, Zeng H, Bray F, et al. Cancer statistics in China, 2015. CA Cancer J Clin 2016;66(2):115-32.

2. Bray F, Ferlay J, Soerjomataram I, Siegel RL, Torre LA, Jemal A. Global cancer statistics 2018: GLOBOCAN estimates of incidence and mortality worldwide for 36 cancers in 185 countries. CA Cancer J Clin 2018;68(6):394-424.

3. Zhang Q, Li X, Li Y, Chen S, Shen X, Dong X, et al. Expression of the PTEN/FOXO3a/PLZF signalling pathway in pancreatic cancer and its significance in tumourigenesis and progression. Invest New Drugs 2020;38(2):321-8.

4. Song Y, Li L, Ou Y, Gao Z, Li E, Li X, et al. Identification of genomic alterations in oesophageal squamous cell cancer. Nature 2014;509(7498):91-5.

5. Li QQ, Wang G, Liang H, Li JM, Huang F, Agarwal PK, et al. beta-Elemene promotes cisplatin-induced cell death in human bladder cancer and other carcinomas. Anticancer Res 2013;33(4):1421-8.

6. Zhang F, Xu L, Qu X, Zhao M, Jin B, Kang J, et al. Synergistic antitumor effect of beta-elemene and etoposide is mediated via induction of cell apoptosis and cell cycle arrest in non-small cell lung carcinoma cells. Mol Med Rep 2011;4(6):1189-93.

7. Li QQ, Lee RX, Liang H, Wang G, Li JM, Zhong Y, et al. Beta-elemene enhances susceptibility to cisplatin in resistant ovarian carcinoma cells via downregulation of ERCC-1 and XIAP and inactivation of JNK. Int J Oncol 2013;43(3):721-8.

8. Zhang R, Pan T, Xiang Y, Zhang M, Feng J, Liu S, et al. betaElemene Reverses the Resistance of p53-Deficient Colorectal Cancer Cells to 5-Fluorouracil by Inducing Pro-death Autophagy and Cyclin D3-Dependent Cycle Arrest. Front Bioeng Biotechnol 2020;8:378. 
9. Zhu TZ, Li XM, Luo LH, Song ZQ, Gao X, Li ZQ, et al. beta-elemene inhibits stemness, promotes differentiation and impairs chemoresistance to temozolomide in glioblastoma stem-like cells. Int J Oncol 2014;45(2):699-709.

10. Zhan YH, Liu J, Qu XJ, Hou KZ, Wang KF, Liu YP, et al. $\beta$-Elemene induces apoptosis in human renal-cell carcinoma 786-0 cells through inhibition of MAPK/ERK and PI3K/ Akt/mTOR signalling pathways. Asian Pac J Cancer Prev 2012;13(6):2739-44.

11. Yu Z, Wang R, Xu L, Xie S, Dong J, Jing Y. $\beta$-Elemene piperazine derivatives induce apoptosis in human leukemia cells through downregulation of c-FLIP and generation of ROS. PLoS One 2011;6(1):e15843.

12. Liang Y, Li S, Zheng G, Zhang L. Beta-elemene suppresses the malignant behavior of esophageal cancer cells by regulating the phosphorylation of AKT. Acta Histochem 2020;122(4):151538.

13. Alizada M, Li J, Aslami H, Yang D, Korchuganova T, Xu YH. Beta-elemene inhibits the proliferation and migration of human glioblastoma cell lines via suppressing ring finger protein 135 . Balkan J Med Genet 2020;23(1):43-49.

14. Gan D, He W, Yin H, Gou X. Beta-elemene enhances cisplatininduced apoptosis in bladder cancer cells through the ROSAMPK signaling pathway. Oncol Lett 2020;19(1):291-300.

15. Zhao L, Wei J, Wang S, Lang T, Shi X, Shan Z, et al. Betaelemene inhibits differentiated thyroid carcinoma metastasis by reducing cellular proliferation, metabolism and invasion ability. Ann Transl Med 2020;8(19):1232.

16. Deng M, Liu B, Song H, Yu R, Zou D, Chen Y, et al. $\beta$-Elemene inhibits the metastasis of multidrug-resistant gastric cancer cells through miR-1323/Cbl-b/EGFR pathway. Phytomedicine 2020;69:153184.

17. Pan Y, Wang W, Huang S, Ni W, Wei Z, Cao Y, et al. Betaelemene inhibits breast cancer metastasis through blocking pyruvate kinase M2 dimerization and nuclear translocation. J Cell Mol Med 2019;23(10):6846-58.

18. Chen W, Lu Y, Wu J, Gao M, Wang A, Xu B. Beta-elemene inhibits melanoma growth and metastasis via suppressing vascular endothelial growth factor-mediated angiogenesis. Cancer Chemother Pharmacol 2011;67(4):799-808.

19. Zhao WJ, Zhao ZA, Wang QY, Li XB, Xie C, Cao ZS. The effects of beta-elemene on rabbit VX2 laryngeal carcinoma and factors associated with tumor growth and metastasis. Zhonghua Er Bi Yan Hou Tou Jing Wai Ke Za Zhi 2016;51(8):606-10.

20. Lim S, DG Kim, S. Kim. ERK-dependent phosphorylation of the linker and substrate-binding domain of HSP70 increases folding activity and cell proliferation. Exp Mol Med 2019;51(9):1-14.

21. Song J, M Takeda, RI Morimoto. Bag1-Hsp70 mediates a physiological stress signalling pathway that regulates Raf-1/ ERK and cell growth. Nat Cell Biol 2001;3(3):276-82.

22. Antognelli C, Gambelunghe A, Muzi G, Talesa VN. Glyoxalase I drives epithelial-to-mesenchymal transition via argpyrimidine-modified Hsp70, miR-21 and SMAD signalling in human bronchial cells BEAS-2B chronically exposed to crystalline silica Min-U-Sil 5: Transformation into a neoplasticlike phenotype. Free Radic Biol Med 2016;92:110-25.
23. Cao Y, Gao L, Tang R, Zhang W. Hsp70 protects human trabecular meshwork cells injury induced by UVB through Smad pathway. Pharmazie 2017;72(6):334-7.

24. Yu F, Tong LJ, Cai DS. Sevoflurane inhibits neuronal apoptosis and expressions of HIF-1 and HSP70 in brain tissues of rats with cerebral ischemia/reperfusion injury. Eur Rev Med Pharmacol Sci 2020;24(9):5082-90.

25. Lyu Q, Wawrzyniuk M, Rutten VP, van Eden W, Sijts AJ, Broere F. Hsp70 and NF-kB mediated control of innate inflammatory responses in a canine macrophage cell line. Int $\mathrm{J}$ Mol Sci 2020;21(18):6464.

26. Dimas DT, Perlepe CD, Sergentanis TN, Misitzis I, Kontzoglou $\mathrm{K}$, Patsouris E, et al. The prognostic significance of Hsp70/ Hsp90 expression in breast cancer: a systematic review and meta-analysis. Anticancer Res 2018;38(3):1551-62.

27. Joo M, Chi JG, Lee H. Expressions of HSP70 and HSP27 in hepatocellular carcinoma. J Korean Med Sci 2005;20(5):82934.

28. Xu B, Li S, Fang Y, Zou Y, Song D, Zhang S, et al. Proprotein convertase subtilisin/kexin type 9 promotes gastric cancer metastasis and suppresses apoptosis by facilitating MAPK signaling pathway through HSP70 up-regulation. Front Oncol 2021;10:2830.

29. Wang XP, Liu GZ, Song AL, Chen RF, Li HY, Liu Y. Expression and significance of heat shock protein 70 and glucose-regulated protein 94 in human esophageal carcinoma. World J Gastroenterol 2005;11(3):429-32.

30. Hanahan D, Weinberg RA. Hallmarks of cancer: the next generation. Cell 2011;144(5):646-74.

31. Yang L, Yu Y, Xiong Z, Chen H, Tan B, Hu H. Downregulation of SEMA4C inhibit epithelial-mesenchymal transition (EMT) and the invasion and metastasis of cervical cancer cells via inhibiting transforming growth factor-beta 1 (TGF$\beta 1$ )-induced hela cells p38 mitogen-activated protein kinase (MAPK) activation. Med Sci Monit 2020;26:e918123-1.

32. Singh V, Singh AP, Sharma I, Singh LC, Sharma J, Borthakar $\mathrm{BB}$, et al. Epigenetic deregulations of $\mathrm{Wnt} / \mathrm{beta}-\mathrm{catenin}$ and transforming growth factor beta-Smad pathways in esophageal cancer: Outcome of DNA methylation. J Cancer Res Ther 2019;15(1):192-203.

33. Qi YJ, Jiao YL, Chen P, Kong JY, Gu BL, Liu K, et al. Porphyromonas gingivalis promotes progression of esophageal squamous cell cancer via TGFbeta-dependent Smad/YAP/TAZ signaling. PLoS Biol 2020;18(9):e3000825.

34. Chen L, Guo P, He Y, Chen Z, Chen L, Luo Y, et al. HCCderived exosomes elicit HCC progression and recurrence by epithelial-mesenchymal transition through MAPK/ERK signalling pathway. Cell Death Dis 2018;9(5):1-7.

This is an open access article distributed under the terms of the Creative Commons Attribution-NonCommercial-ShareAlike 3.0 License, which allows others to remix, tweak, and build upon the work non-commercially, as long as the author is credited and the new creations are licensed under the identical terms

This article was originally published in a special issue, "Diagnostic and Therapeutic Advances in Biomedical Research and Pharmaceutical Sciences"

Indian J Pharm Sci 2021:83(5) spl issue “85-93" 